\title{
They Like to Play Games? Student Interest of Serious Game-Based Assessments for Language Literacy
}

\author{
Rohani Aziz",2, Helmi Norman"1,3*, Norazah Nordin1, Fatin Nabilah Wahid1, Nor Azizah Tahir1 \\ ${ }^{1}$ Faculty of Education, Universiti Kebangsaan Malaysia (UKM), Bandar Baru Bangi, Selangor, Malaysia \\ ${ }^{2}$ Examination Syndicates, Ministry of Education, Selangor, Malaysia \\ ${ }^{3}$ Center for Teaching and Learning Technologies, UKM, Selangor, Malaysia \\ Email: *helmi.norman@ukm.edu.my
}

How to cite this paper: Aziz, R., Norman, H., Nordin, N., Wahid, F. N., \& Tahir, N. A. (2019). They Like to Play Games? Student Interest of Serious Game-Based Assessments for Language Literacy. Creative Education, 10, 3175-3185.

https://doi.org/10.4236/ce.2019.1012241

Received: October 21, 2019

Accepted: November 26, 2019

Published: November 29, 2019

Copyright $\odot 2019$ by author(s) and Scientific Research Publishing Inc. This work is licensed under the Creative Commons Attribution International License (CC BY 4.0).

http://creativecommons.org/licenses/by/4.0/

\begin{abstract}
A renewal of interest in the area of gamification was found in a generation of digital natives whom were born with the mainstreaming of high-speed, broadband Internet connectivity and gaming is such a common culture among them. In contrast, common standardized test applied in current education setting serves as a barrier to the learning innovation, technology expansion and digital culture resulting in increasing anxiety among students. In addition, the traditional approach of assessment has been reported to fail in meeting the digital needs of student learning in $21^{\text {st }}$ century learning setting. The purpose of this study is to explore the perception among students on serious game-based educational assessment as an alternative assessment in early language literacy. This study applied a quantitative survey design to gain 122 primary level student's perception on serious games for language literacy assessment. The findings show that respondents show interest in applying serious game-based assessment as part of an alternative assessment for language literacy context, which is in contrast with the nature of standardized tests in typical formal educational setting. More than 75 percent respondents agreed and gave positive feedback of satisfaction towards the use of serious game-based assessment for language literacy learning. The study was relevant in order to meet the new and changing demands in future assessment approaches. It is hoped that the implications of this study can serve as a guideline for the design and development of future assessment in language literacy through alternative assessment for primary school students.
\end{abstract}

\section{Keywords}

Serious Games, Game-Based Assessment, Early Language Literacy, Primary 
Education, Alternative Assessment

\section{Introduction}

The United Nations 2030 Agenda for Sustainable Development, or Sustainable Development Goals (SDGs), Education 2030 Framework (UN, 2019) for action offer, the development of more robust comprehensive assessment systems to assess learning outcomes at critical points, including assessment of foundational reading, writing and numeracy skills as well as non-cognitive skill and designing formative assessments as an integral part at the teaching and learning process. This notion meets Malaysian education vision to adopt new methods of teaching and learning in line with the needs of today's technologically advanced generation of students, to better prepare students for any form of assessment.

The issue of the student's achievement in the language literacy among primary school students continues until now. Therefore, many efforts have been done to improve language literacy skills among lower level of students in primary school. As to spark the interest and motivation in improving language literacy achievement among children, serious game-based assessment is proposed to accommodate students' interests towards technological kits in a pragmatic learning approach. In the context of education, serious games are an educational game-based approach that could potentially help students to master the learning process in formative form of assessment (Serrano-Laguna, Martínez-Ortiz, Haag, Regan, Johnson, \& Fernández-Manjón, 2017; Adnan \& Ritzhaupt, 2018).

\section{Overview}

\subsection{What Sparks Students' Interest in Games?}

Games have been reported to increase levels of motivation for its users (Kim \& Shute, 2015). However, (Hamari, 2013) has empirically stated the reasons and motivations as to why people use games are expected to vary, either between the purposes of games or between games for entertainment and those for instrumental purposes. (Merikivi, Tuunainen, \& Duyen, 2017) mentioned that perceived enjoyment as a motive, which thrives gamers to immersed in playing game, while (Hamari, 2017) has stated the important factors to associate fun and usefulness in his study of why do people play games.

Technologies also open new windows of opportunities when applied in assessments. According to (Bennett, Dawson, Bearman, Molloy, \& Boud, 2017), technology integration in assessment is needed to understand routine assessment design work to stimulate motivation and engagement in teaching and learning process. Meanwhile, in another study, (Nikou \& Economides, 2017) demonstrated that perceived trust positively influences technological-based assessment acceptance. Thus, games served as such an innovative tool to hook 
student's interests and demonstrate meaningful learning and cognition (Perkins, 2016), therefore reflect on how people learn in various methods. Moreover, the use of games in education generally has a positive impact on students' learning (Sadiq, 2010; Çankaya \& Karamete, 2009; De Freitas, 2018).

\subsection{The Potential of Serious Game-Based Assessment}

Games have been a part of educational strategies for decades. However, with technological advances in Fourth Industrial Revolution (4IR), serious games have recently emerged as an assessment tool for learning. Serious games is referred to as games that can potentially 1 ) to be fun and entertaining, and 2) to be educational (Bellotti, Kapralos, Lee, Moreno-Ger, \& Berta, 2013). (Coovert, Winner, Bennett, \& Howard, 2012) stated that serious games refers to computerized games and advanced video graphics systems utilized for non-entertainment purposes and whose focus is on learning and training or educational and behavioral change.

To date, studies by scholars such as (Malaquias, Malaquias, Fernanda Francielle de Oliveira; Borges, \& Zambra, 2018; Kato \& de Klerk, 2017; Garneli, Giannakos, \& Chorianopoulos, 2017), provides a good exposure to serious games applications as a measuring tool in the evaluation and assessment of the learning process. The serious game-based assessment approach is seen as giving students the opportunity to undergo a less formal test process while still providing accurate information on their achievement. In the study conducted by (Malaquias, Malaquias, Fernanda Francielle de Oliveira, Borges, \& Zambra, 2018), the results show that potential benefits of serious games on the academic achievement of students provides empirical evidence on the impact of serious games on students' self-discipline. It was found that students who were able to demonstrate the maximum ability in the serious games played also had a high reliability index in terms of their own discipline. Meanwhile, a study conducted by (Kato \& de Klerk, 2017) concludes that the assessment approach or educational assessment through serious games can be part of an effective formative evaluation because of its interactive testing features in line with innovative instructional technology, which is also can act as an alternative assessment tool to be further implemented as summative assessments and standardized assessments.

\section{Methodology}

This study implemented a need analysis study based on future user perception on the previous literacy skill and ICT skill needed, as well as user satisfaction analysis of the serious game-based assessment applied. Therefore, the survey technique was implemented with 122 respondents. In the analysis phase, the need analysis was carried out. The first part if this survey consists of the information on the application requirements of the Serious Games application of the Malay Language literacy assessment. The second part of this survey consists of 
user satisfaction analysis on the overall serious game-based assessment develop for this study. The survey was conducted on students of primary level using binary scale as according to the respondent level of cognitive. The data was analyzed statistically and two set of reports were performed; 1) Need analysis, and 2) User satisfaction.

\section{Research Finding}

The demographical findings are as the following. It involved a sample of 122 children throughout Malaysia.

Based on Figure 1 shown, the majority of respondents were from rural areas with 63.5 percent while 34.5 percent of respondents were urban children. 52.9 percent of the respondents were girls, while 47.1 percent of the respondents were boys. The main job of the father/guardian of the respondents is a public worker of 41.3 percent. 33.1 percent are private employees, 24.8 percent are self-employed fathers/guardians, while 0.8 percent of fathers/guardians do not work. With regards to the household income of parents/guardians, it was found that 51.2 percent of the respondents were in the Medium40 (M40) and Top20 (T20) household groups while 48.8 percent of the respondents were among households earning less than RM3855 in the B40 household group. 38.3 percent of respondents aged 7 years, while 9.7 percent of respondents aged 9 years.

Based on Figure 2, it was discovered that the majority of respondents have at least a home cellphone at 86 or 71.1 percent. A total of 61 or 50.4 percent of respondents revealed that they also had a computer or laptop or notebook. Only 30 respondents or 24.8 percent have mobile phones, while 2 or 1.7 percent of respondents do not have any computer or mobile device.

\subsection{Perception Analysis}

The aim of the first section of the survey, was to obtain information on child readiness on any form of assessment in the existing formal education system as well as their perceptions of the self-assessment system. As such, six items were developed to achieve the purpose of obtaining such information. Therefore, Table 1

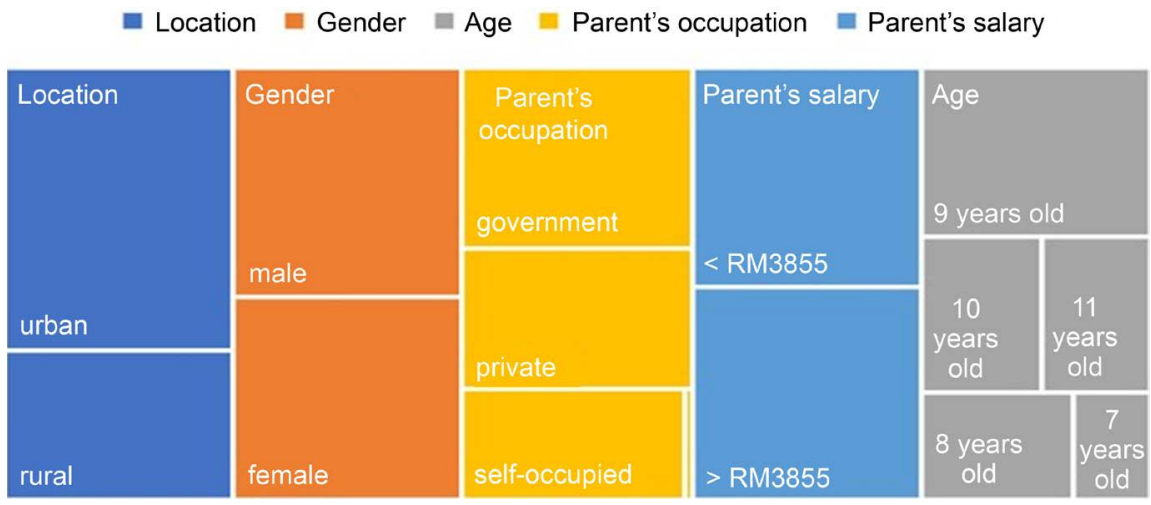

Figure 1. Respondent demographic analysis. 


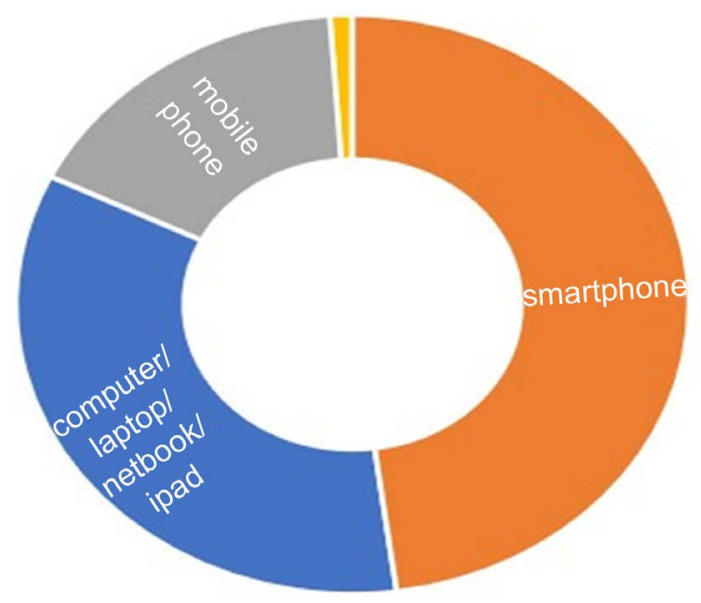

Figure 2. Type of gadget used at home.

Table 1. Student perception on Malay Language Literacy Assessment.

\begin{tabular}{|c|c|c|c|}
\hline & \multirow{2}{*}{ Item } & \multicolumn{2}{|c|}{ Percentage (\%) } \\
\hline & & Not agree & Agree \\
\hline A1 & I'm not afraid of the examination & 34.71 & 65.29 \\
\hline A2 & I can answer the exam questions well without teacher guidance & 20.66 & 79.34 \\
\hline A3 & I like to answer reading test question & 21.49 & 78.51 \\
\hline A4 & I like to answer writing test question & 23.97 & 76.03 \\
\hline A5 & I can do language exercises all by myself at home & 28.93 & 71.07 \\
\hline A6 & $\begin{array}{l}\text { I will enjoy if I can do language test using the technological tool } \\
\text { (example: computer) }\end{array}$ & 44.63 & 55.37 \\
\hline
\end{tabular}

shows descriptive analysis of students' perceptions on the existing language literacy assessment they have been through.

Table 1 shows the perception of children on the existing language literacy assessment and the tendency of children to implement self-empowerment and enrichment activities. Based on the questionnaire, more than 65 percent of respondents were positive towards the statement presented in this section. In conclusion, the findings of the student perception construct on Malay Literacy Assessment give a clear picture to the researcher on the development needs of the Serious Games Literacy Malay Language Instrument as a good alternative as well as instruments that would be of value to the existing forms of assessment and assessment of language.

The second part of the questionnaire (Table 2) looks at perception, interest and tendency of children towards Online/Video Games. The findings for this construct could potentially be crucial in Serious Games development in Malay literacy instruments.

Table 2 shows the perception, interest and tendency of children against game games either online or in video games. The findings of the questionnaire showed that over 50 percent agreed with all the statements presented in this construct. In 
Table 2. Students' perception and interest on Online/Video Games.

\begin{tabular}{llcc}
\hline & & \multicolumn{2}{c}{ Percentage (\%) } \\
\cline { 3 - 4 } & & Not agree & Agree \\
\hline B7 & I used to play Online/Video Games & 10.74 & 89.26 \\
B8 & I always play Online/Video Games in my free time & 26.45 & 73.55 \\
B9 & I enjoy playing Online/Video Games & 10.74 & 89.26 \\
B10 & I like playing colorful Online/Video Games & 12.40 & 87.60 \\
B11 & I like to play Online/Video Games with many characters & 19.83 & 80.17 \\
B12 & I play Online/Video Games on my smartphone/computer/laptop. & 11.57 & 88.43 \\
B13 & I am very good at playing Online/Video Games. & 40.50 & 59.50 \\
B14 & I played frequently Online/Video Games in the past four weeks. & 49.59 & 50.41 \\
B15 & I will continue playing Online/Video Games in the future. & 27.27 & 72.73 \\
\hline
\end{tabular}

conclusion, the analysis of the findings of the perceptions, interest and tendency of respondents to Online/Video Games shows a high inclination of children to any form of Online/Video Games game. This is supported by a high percentage of consent exceeding 70 percent of all statements that have been raised.

The third part of the survey (Table 3 ) investigates children's perceptions, interests and preferences towards technological tools.

Table 3 shows the perceptions, interests and preferences of children towards technological tools. Based on the findings of the survey, more than 70 percent of respondents agreed with all the statements submitted. 76.86 percent of respondents agreed that the use of the device of the technology device for example cellphone or computer is a good thing. 85.95 respondents agreed that the use of technology device tools such as mobile phones or computers can make work or life more attractive. In fact, 86.78 percent of respondents acknowledge that the use of technology device tools such as mobile phones or computers is fun and 80.17 percent of respondents acknowledge that they like to use technology devices such as mobile phones and computers in everyday life. In summary, the findings analysis for this construct shows that the majority of respondents are very optimistic and positive towards the use of technology in their daily lives especially in the learning aspects.

\subsection{Serious-Game Based Assessment Implementation Phase}

Table 3 shows descriptive analysis of students' perceptions on the examination system in the form of examination as well as the existing language literacy filters they have been through (Figure $3 \&$ Figure 4 ).

\subsection{User's Perception towards Serious Game-Based Assessment}

122 perception's analysis on the serious game-based language literacy assessment were analyzed as shown in the tables below. The findings obtained as user implement the application and evaluate the application on the questionnaire distributed. 
Table 3. Student perception and interest on technology (device/gadget).

\begin{tabular}{llcc}
\hline & \multicolumn{1}{c}{ Item } & \multicolumn{2}{c}{ Percentage (\%) } \\
\cline { 3 - 4 } & & Not agree & Agree \\
\hline C1 & Using a technology device (mobile/computer) device is a good thing. & 23.14 & 76.86 \\
C2 & Using a technology device (mobile/computer) device is a good thing. & 14.05 & 85.95 \\
C3 $\quad \begin{array}{l}\text { Using technology device tools (mobile/computer) makes more } \\
\text { work/life more attractive. }\end{array}$ & 13.22 & 86.78 \\
C4 $\quad \begin{array}{l}\text { I like to use the technology device (mobile/computer) device in life daily. } \\
\text { C5 }\end{array}$ & $\begin{array}{l}\text { I look forward to using the technology device (mobile/computer) } \\
\text { device in learning activity. }\end{array}$ & 20.66 & 79.34 \\
\hline
\end{tabular}

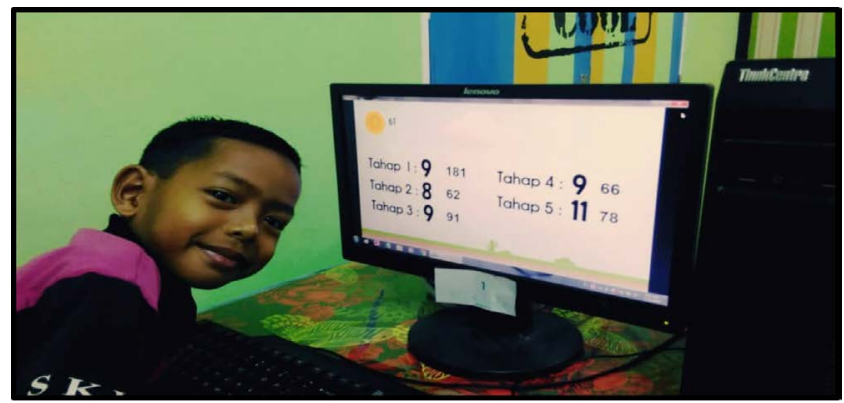

Figure 3. Students trying out the serious game-based language literacy assessment.

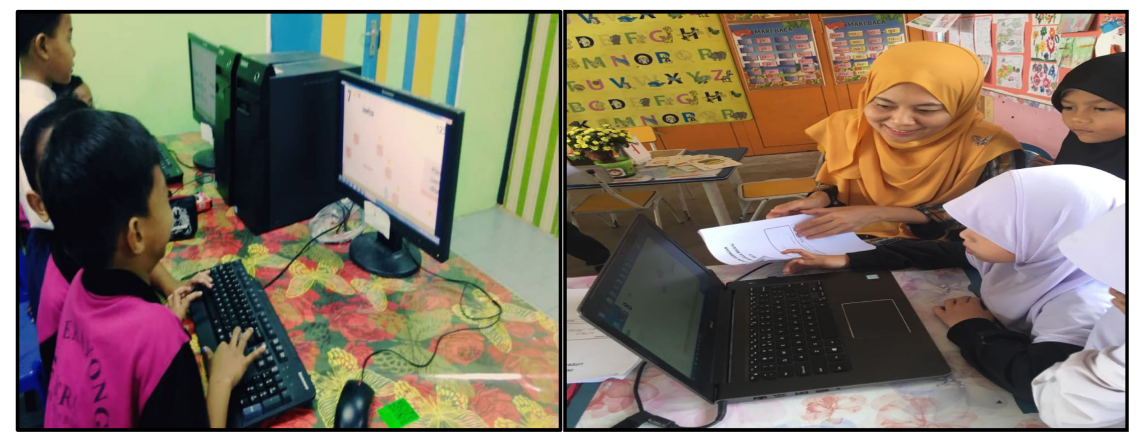

Figure 4. Users achievement in the serious game-based language literacy assessment.

The findings show user satisfaction and perception on the overall application develop for this study.

\subsubsection{User Perception on Serious Games as an Alternative Assessment}

Five items were used to determine user perception towards alternative assessment as part of the language literacy formative assessment as follow;
1. I like to study/answer the test this way
2. I think it's easy to learn/answer the test this way
3. I'm ready to repeat this game at any time
4. I can play this game without the guidance of others
5. I like to repeat the test to improve my performance 
Based on Figure 5(a) on the aspect of alternative assessment, more than 90 percent of respondents agreed with the statements stated. The average respondents' consent to this construct was 90.8 per cent with 96.6 per cent respondents admitting that they liked learning or responding to tests using these serious game rules. While 95.7 percent of respondents acknowledge that they are ready to repeat the test at any time. However, more than 20 percent of respondents acknowledge that they need the guidance of others to use serious games application for this Malay literacy assessment instrument.

\subsubsection{User's Perception on Application Clarity}

Six items were used to determine user perception towards application clarity on serious game-based assessment develop as follow;

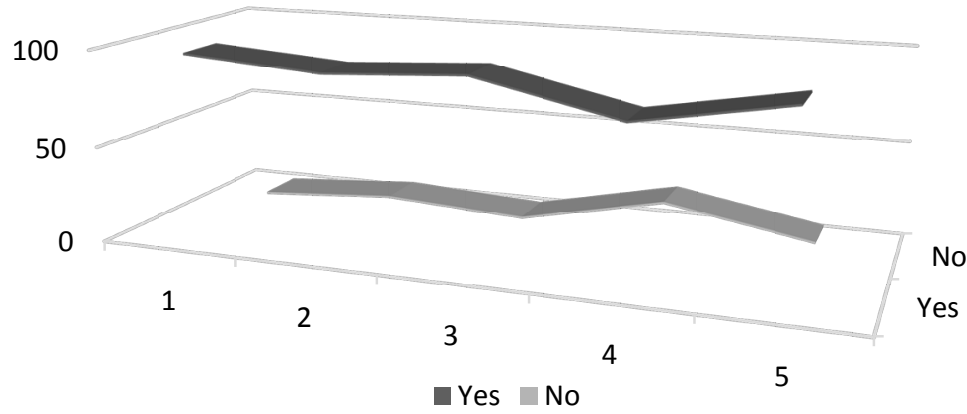

(a)

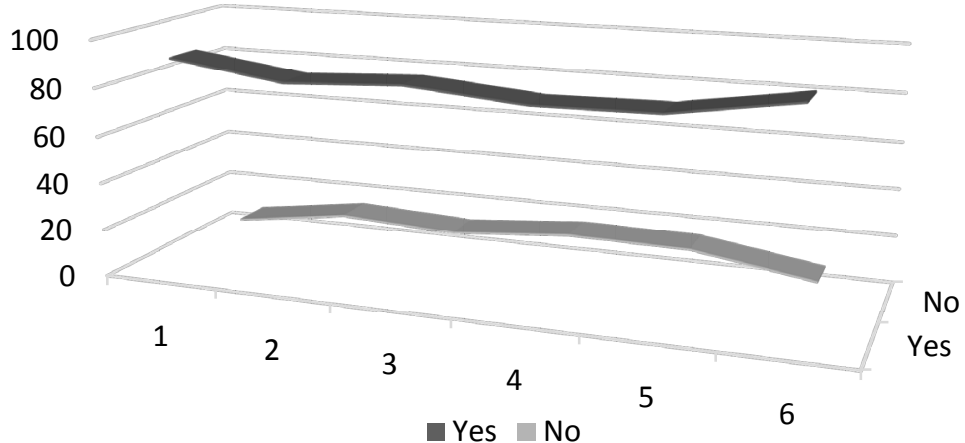

(b)

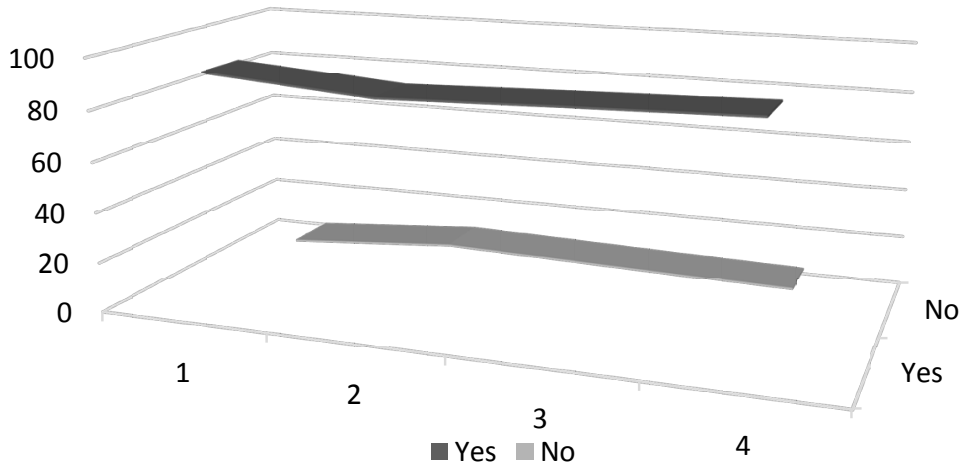

(c)

Figure 5. (a) Alternative assessment; (b) Application clarity; (c) Emotional stimulus. 


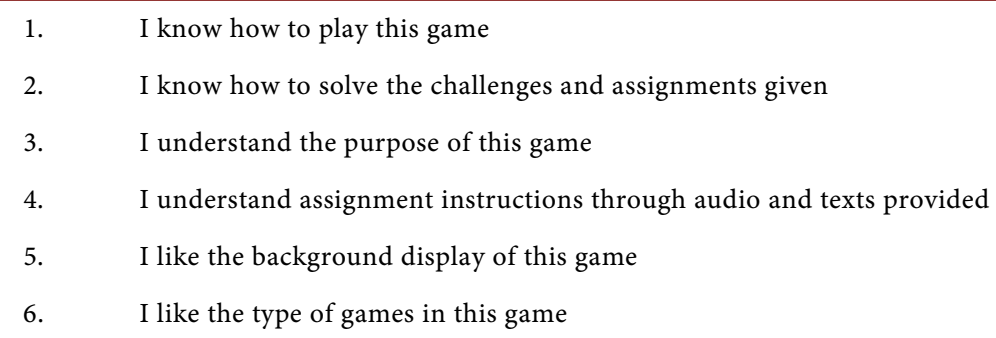

Based on Figure 5(b), the application clarity aspect, over 80 percent of respondents agreed with the statements expressed. The average respondents' consent to this construct was 86.9 percent. 91.5 percent of respondents admit that they really love the type of games in this serious games instrument.

\subsubsection{User's Perception on Serious Games as an Emotional Stimulus}

Five items were used to determine user's perception on serious games as an emotional stimulus, as follow;

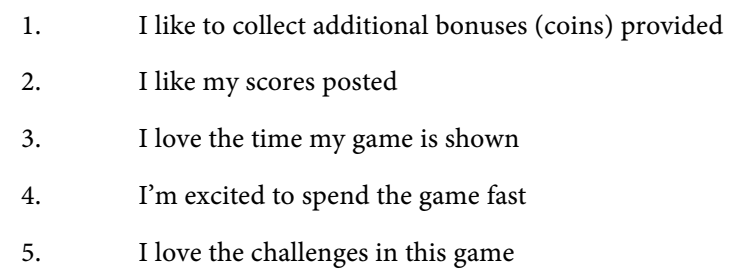

Based on Figure 5(c), in terms of emotional stimulus, more than 85 percent of respondents agreed with the statements expressed. The average respondent's consent to this construct was 90.48 percent. 93 per cent of respondents admit that it's like collecting additional bonuses (collecting coins) set in the game challenge. While 91.3 percent of respondents acknowledged that they were excited to spend the game fast.

\section{Discussion and Conclusions}

In summary, the finding analysis shows that the majority of respondents are very optimistic and positive towards the use of technology in their daily lives especially in the aspects of learning. In addition, the findings of this study provide evidence of respondent's positive attitude towards current literacy assessment conducted. Hence, it is correlated; high tendency of respondents to the technological devices matched their tendencies in video/online games. The finding also shows positive perceptions towards testing and assessments of literacy and provides a good justification for the need to develop the Serious Games instrument of language literacy Malay parallel with the needs of digital skills among digital native.

For the analysis of the users' perceptions of these serious Malay literacy games instruments, more than 75 percent of respondents agreed with all the statements expressed in the questionnaire distributed. This extremely high percentage of 
consensus analysis provides an overview of the quality of serious games produced in parallel with the objectives set. These findings also show the readiness and inclination of pupils as early as the primary school level for the process and form of technology-based learning.

In sum, the study has described the design and development of an online game for learning Malay language in Malaysian primary school. In addition, this study has identified the perception of the existing assessment and availability of technology, as well as an optimistic and positive response of students towards the use of technology in their daily lives especially in the learning aspect (Adnan \& Ritzhaupt, 2018; Andersen, Na-songkhla, Hasse, Nordin, \& Norman, 2018; Nordin, Norman, \& Hamdan, 2018). Furthermore, this study has discovered about the positive attitude of the respondents towards the form of literacy assessment conducted. Therefore, the finding of this study signifies the need to develop a Serious Games instrument of language literacy Malay in line with the needs of digital skills in children to implement the future approach of language learning assessment for Malaysian primary school settings (Nordin, Norman, \& Hamdan, 2018; Norman, Nordin, Din, Ally, \& Dogan, 2015). However, further studies are needed, to establish the notion of informal and formative assessment as a future type of a promising approach of alternative assessment, and also refine the implementation of serious game-based assessment application for specific target users.

\section{Acknowledgements}

This research is funded by the Translational MRUN Rakan-RU Program Grant (Grant No. MRUN-RAKAN RU-2019-003/2) and Dana Pecutan Penerbitan FPend (Grant No. PP-FPEND-2019).

\section{Conflicts of Interest}

The authors declare no conflicts of interest regarding the publication of this paper.

\section{References}

(UN) United Nations (2019). Transforming Our World: The 2030 Agenda for Sustainable Development United Nations United Nations Transforming Our World: The 2030 Agenda for Sustainable Development.

Adnan, N. H., \& Ritzhaupt, A. D. (2018). Software Engineering Design Principles Applied to Instructional Design: What Can We Learn from Our Sister Discipline? TechTrends, 62, 77-94. https://doi.org/10.1007/s11528-017-0238-5

Andersen, B. L., Na-songkhla, J., Hasse, C., Nordin, N., \& Norman, H. (2018). Perceptions of Authority in a Massive Open Online Course: An Intercultural Study. International Review of Education, 64, 221-239. https://doi.org/10.1007/s11159-018-9708-Z

Bellotti, F., Kapralos, B., Lee, K., Moreno-Ger, P., \& Berta, R. (2013). Assessment in and of Serious Games: An Overview. Advances in Human-Computer Interaction, 2013, Article ID: 136864. https://doi.org/10.1155/2013/136864 
Bennett, S., Dawson, P., Bearman, M., Molloy, E., \& Boud, D. (2017). How Technology Shapes Assessment Design: Findings from a Study of University Teachers. British Journal of Educational Technology, 48, 672-682. https://doi.org/10.1111/bjet.12439

Çankaya, S., \& Karamete, A. (2009). The Effects of Educational Computer Games on Students' Attitudes towards Mathematics Course and Educational Computer Games. Procedia-Social and Behavioral Sciences, 1, 145-149. https://doi.org/10.1016/j.sbspro.2009.01.027

Coovert, M. D., Winner, J., Bennett, W., \& Howard, D. J. (2012). Serious Games Are a Serious Tool for Team Research. International Journal of Serious Games, 4.

De Freitas, S. (2018). Are Games Effective Learning Tools? A Review of Educational Games. Educational Technology and Society, 21, 74-84.

Garneli, V., Giannakos, M., \& Chorianopoulos, K. (2017). Serious Games as a Malleable Learning Medium: The Effects of Narrative, Gameplay, and Making on Students' Performance and Attitudes. British Journal of Educational Technology, 48, 842-859. https://doi.org/10.1111/bjet.12455

Hamari, J. (2013). Social Motivations to Use Gamification: An Empirical Study of Gamifying Exercise.

Hamari, J. (2017). Player Types: A Meta-Synthesis (pp. 29-53).

Kato, P., \& de Klerk, S. (2017). Serious Games for Assessment: Welcome to the Jungle. Journal of Applied Testing Technology, 18, 1-6.

Kim, Y. J., \& Shute, V. J. (2015). The Interplay of Game Elements with Psychometric Qualities, Learning, and Enjoyment in Game-Based Assessment. Computers \& Education, 87, 340-356. https://doi.org/10.1016/j.compedu.2015.07.009

Malaquias, R. F., de Oliveira Malaquias, F. F., Borges Junior, D. M., \& Zambra, P. (2018). The Use of a Serious Game and Academic Performance of Undergraduate Accounting Students: An Empirical Analysis. Turkish Online Journal of Distance Education, 19, 117-127. https://doi.org/10.17718/tojde.415825

Merikivi, J., Tuunainen, V., \& Duyen, N. (2017). What Makes Continued Mobile Gaming Enjoyable? SC. Comput. Human Behav.

Nikou, S. A., \& Economides, A. A. (2017). Mobile-Based Assessment: Integrating Acceptance and Motivational Factors into a Combined Model of Self-Determination Theory and Technology Acceptance. Computers in Human Behavior, 68, 83-95.

https://doi.org/10.1016/j.chb.2016.11.020

Nordin, N., Norman, H., \& Hamdan, F. (2018). Quality Education with Instructional Design via Massive Open Online Courses. Advanced Science Letters, 24, 2541-2545. https://doi.org/10.1166/asl.2018.11000

Norman, H., Nordin, N., Din, R., Ally, M., \& Dogan, H. (2015). Exploring the Roles of Social Participation in Mobile Social Media Learning: A Social Network Analysis. The International Review of Research in Open and Distributed Learning, 16, 205-224. https://doi.org/10.19173/irrodl.v16i4.2124

Perkins, C. (2016). Earthquake: Game-Based Learning for 21.

Sadiq, I. (2010). Effects of Online Games on Student Performance in Undergraduate Physics. ProQuest Diss. Theses.

Serrano-Laguna, A., Martínez-Ortiz, I., Haag, J., Regan, D., Johnson, A., \& Fernández-Manjón, B. (2017). Applying Standards to Systematize Learning Analytics in Serious Games. Computer Standards \& Interfaces, 50, 116-123.

https://doi.org/10.1016/j.csi.2016.09.014 